ARTICLE

https://doi.org/10.1038/s41467-020-19195-w

\title{
Decarboxylative thiolation of redox-active esters to free thiols and further diversification
}

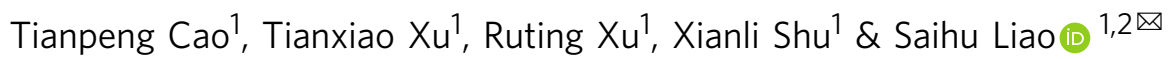

Thiols are important precursors for the synthesis of a variety of pharmaceutically important sulfur-containing compounds. In view of the versatile reactivity of free thiols, here we report the development of a visible light-mediated direct decarboxylative thiolation reaction of alkyl redox-active esters to free thiols based on the abundant carboxylic acid feedstock. This transformation is applicable to various carboxylic acids, including primary, secondary, and tertiary acids as well as natural products and drugs, forging a general and facile access to free thiols with diverse structures. Moreover, the direct access to free thiols affords an advantage of rapid in situ diversification with high efficiency to other important thiol derivatives such as sulfide, disulfide, thiocyanide, thioselenide, etc.

\footnotetext{
${ }^{1}$ Key Laboratory of Molecule Synthesis and Function Discovery (Fujian Province University), College of Chemistry, Fuzhou University, 350108 Fuzhou, China. ${ }^{2}$ State Key Laboratory of Photocatalysis on Energy and Environment, College of Chemistry, Fuzhou University, 350108 Fuzhou, China.

$凶_{\text {email: shliao@fzu.edu.cn }}$
} 
T he construction of molecule libraries with structural and functional diversity is crucial for the study in the context of chemical biology and drug discovery ${ }^{1-3}$. Thiols are important precursors for the synthesis of a variety of pharmaceutically important sulfur-containing compounds, including sulfonamides, sulfonyl fluorides, sulfoxides, sulfides, disulfides, and so on, by virtue of their high reactivity and valence labile nature, and widely employed in organic synthesis, polymer preparation, materials science, and biomedicine ${ }^{4-17}$. In fact, besides their well-known roles in protein structure stabilizations ${ }^{18,19}$ and many enzymatic processes ${ }^{20}$, thiol is also one of the most targeted sites in post-translational protein modification (Fig. 1a) (1-23 $^{2}$. Inspired by the versatile reactivity of thiols, we conceived that, based on the feedstock of abundant carboxylic acid, a decarboxylative thiolation of acid-derived redox-active esters (RAEs) ${ }^{24-39}\left(\mathrm{RCO}_{2} \mathrm{~A}^{*}\right)$ to free thiols could forge a novel access to various thiols and related derivatives with considerable structural diversity. In particular, the decarboxylative access to free thiols could allow a further diversification to other sulfur-containing compounds ${ }^{40-42}$ with a multiplied diversity by varying the coupling agents (e.g., with various electrophiles $\mathrm{E}^{+}$, Fig. 1b).
A number of radical C-S bond formation reactions ${ }^{43-49}$ have been reported, including the related decarboxylative transformations pioneered by Barton in $1980 \mathrm{~s}^{46-49}$, but a direct radical thiolation to free thiols remains elusive so far. The challenges for the proposed radical decarboxylative thiolation to free thiols probably lie in the labile nature of free thiols, which can lead to dimerization, undesired hydrogen transfer, and other side reactions $^{43}$. In fact, free thiols are commonly used as hydrogen atom transfer (HAT) catalysts or reagents in radical chemistry ${ }^{50-54}$, and the HAT from a primary alkyl thiol to alkyl radicals is a fast process (ca. $10^{7} \mathrm{M}^{-1} \mathrm{~s}^{-1}$ ) $52-54$. Therefore, in the decarboxylative thiolation process, the desired thiol product (RSH) formed earlier may intercept the newly generated alkyl radicals (R.), thus leading to the undesired alkane (R-H) formation (Fig. 1c). Nevertheless, in radical polymerization, the chain-transfer agents (CTA) employed in reversible addition-fragmentation chain-transfer polymerization can readily alter the radical addition rate by adjusting the $\mathrm{Z}$ group and increase $k_{\text {add }}$ to above $10^{8} \mathrm{M}^{-1} \mathrm{~s}^{-1}$ (Fig. 1, C, below) ${ }^{55,56}$, which inspired us to focus on the sulfur donor search in the beginning. Herein, we report our efforts in the successful identification of aryl thioamides as an effective sulfur donor, and the invention of visible light-mediated direct

\section{a Thiols in functionality transformation and protein modification}

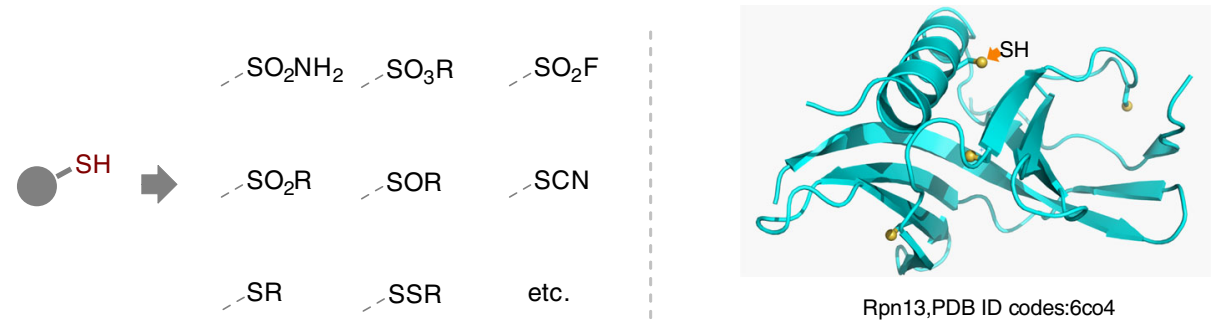

$\mathrm{SH}$ as targeted site in protein modification

b Diversity-oriented decarboxylative thiolation to free thiols (this work)

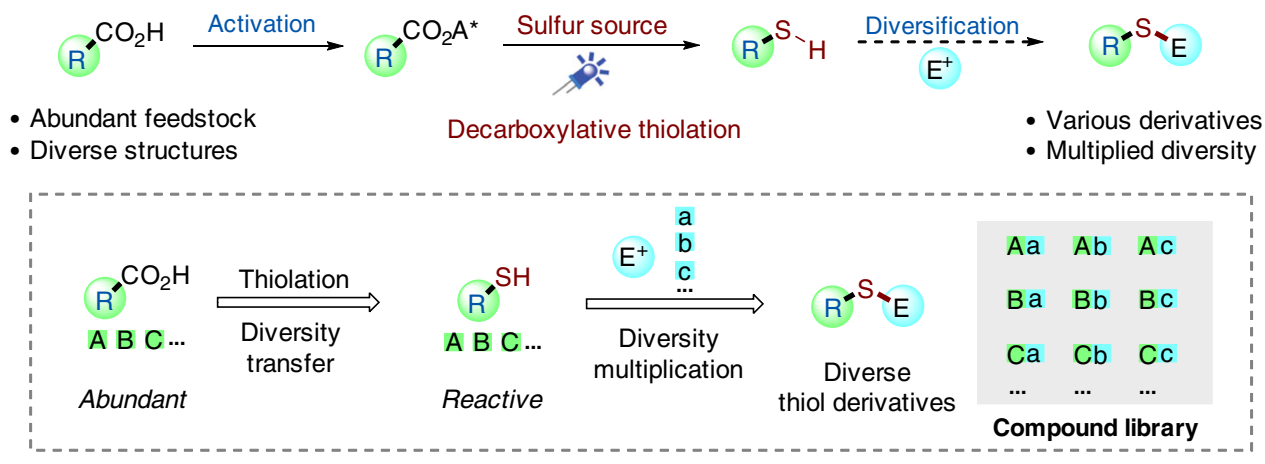

C Mechanistic consideration

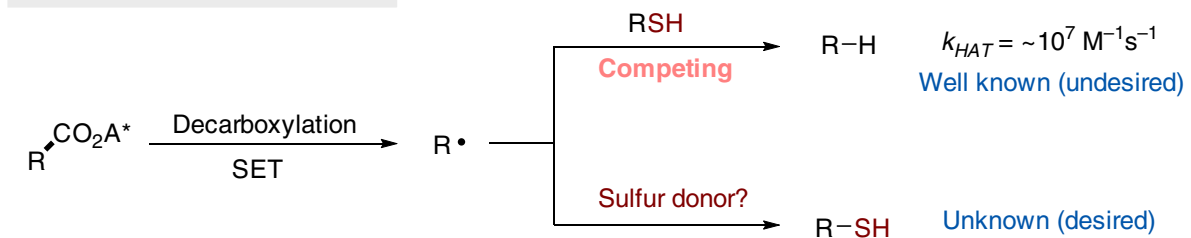

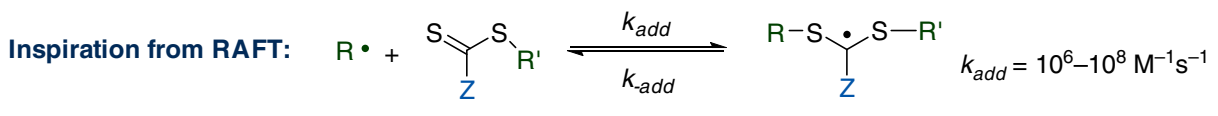

Chain transfer agent

Fig. 1 Reaction design. a Thiols in functionality transformation and protein modification. $\mathbf{b}$ Diversity-oriented decarboxylative thiolation to free thiols. c Mechanistic consideration and the inspiration from reversible addition-fragmentation chain-transfer (RAFT) polymerization. 
decarboxylative thiolation of alkyl RAEs to free thiols. Moreover, further diversification to other thiol derivatives, such as sulfide, disulfide, thiocyanide, and thioselenide via in situ trapping, is also demonstrated.

\section{Results}

Reaction optimization. We commenced our study with the search for sulfur donors suitable for the radical thiolation reaction, by employing dihydrocinnamic acid-derived RAE (1) as the model substrate and Eosin $\mathrm{Y}-\mathrm{Na}_{2}$ /diisopropylethylamine (DIPEA) as the photoredox catalytic system (Table 1). Initially, thiourea 2a, which is frequently used as a sulfur donor in the nucleophilic substitution reactions of alkyl halides 57,58 , was examined first in the reaction, but only the alkane product $3^{\prime}$ was observed (entry 1), indicating the radical reactivity is substantially different from the polar substitution reactions. Other thioureas like $\mathbf{2 b}$ and $\mathbf{2 c}$ were also examined, but neither of them afforded the desired thiol product (entries 2 and 3). We then turned our attention to other types of sulfur donor (for more details about the reaction development, please see the Supplementary Figs. 1-9 and Table 1). To our delight, benzothioamide was found being a promising sulfur donor for this decarboxylative thiolation reaction, and the desired thiol 3 could be obtained as the predominant product in $77 \%$ yield (entry 4). We then carried out several modifications on the phenyl group of benzothioamides (entries 4-6). Electronwithdrawing group $\left(-\mathrm{CF}_{3}, 2 \mathrm{e}\right)$ led to a decreased yield of $35 \%$, while the introduction of an electron-donating group (2f) was found beneficial and further increased the yield to $81 \%$ (entry 5 vs. entry 6). The $\mathrm{N}-\mathrm{H}$ group proved to be crucial for this transformation. Replacement with either one or two methyl groups ( $\mathbf{2} \mathbf{g}$ and $\mathbf{2 h}$ ), both resulted in a sharp drop in yield (entries 7 and 8). Moreover, sulfur powder was also tested, but no desired thiol product was observed (entry 9). With $\mathbf{2 f}$ as the sulfur donor, we conducted a further reaction optimization, including

photocatalyst, solvent, light source, and so on (for details, please see the Supplementary Tables 2 and 3). Other photocatalysts, such as $\mathrm{Ru}(\text { bpy })_{3} \mathrm{Cl}_{2} \cdot 6 \mathrm{H}_{2} \mathrm{O}$ and $\operatorname{Ir}(\mathrm{ppy})_{3}$, gave lower yields (entries 10-13), while Eosin $\mathrm{Y}$ was found equally efficient (entry 14). Running the reaction in $\mathrm{CH}_{3} \mathrm{CN}$ could slightly enhanced the selectivity (entry 15). Without light or photocatalyst, no reaction or a low yield was observed (entries 16 and 17). To our delight, the employment of two equivalents of sulfur donor $2 \mathrm{f}$ could further suppress the undesired alkane formation and increase the yield of the desired thiol product to a decent level of $88 \%$ in the end (entry 18 ).

Substrate scope. With the optimized reaction conditions in hand, we next examined the reaction scope with a variety of primary, secondary, and tertiary acid-derived RAEs (Fig. 2). Some free thiols are volatile and thus isolated in their disulfide form by in situ trapping with diphenyl disulfide. These results are also included in Fig. 2. In cases of primary acids (3-18), we could see a good functional group tolerance. $\mathrm{Br}, \mathrm{Cl}$, ether, ester, and also a triple $\mathrm{C}-\mathrm{C}$ bond are all compatible in the reaction, and the

Table 1 Reaction optimizations for decarboxylative thiolation to free thiolsa.

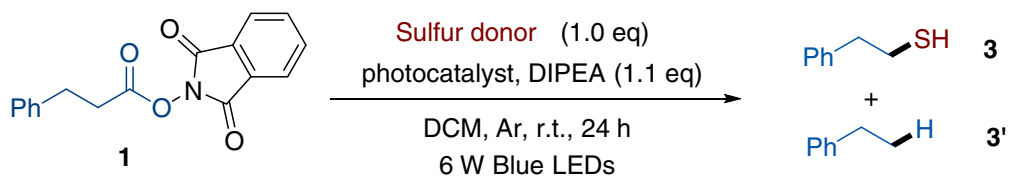

Selected examples of sulfur donor:<smiles>NC(N)=S</smiles>

2a<smiles>NC(=S)c1ccc(C(F)(F)F)cc1</smiles><smiles>S=C1NCCN1</smiles>

2b<smiles>COc1ccc(C(N)=S)cc1</smiles><smiles>S=c1[nH]c2ccccc2[nH]1</smiles>

2c<smiles>CNC(=S)c1ccc(OC)cc1</smiles><smiles>NC(=S)c1ccccc1</smiles>

2d<smiles>CN(C)C(=S)c1ccccc1</smiles>

$2 h$

\begin{tabular}{|c|c|c|c|c|c|}
\hline Entry & Sulfur donor & Yield $\left(3 / 3^{\prime}\right)^{b}$ & Entry & Catalyst & Yield $\left(3 / 3^{\prime}\right)^{b}$ \\
\hline 1 & $2 a$ & $0 / 81$ & 10 & {$\left[\mathrm{Ru}(\mathrm{bpy})_{3}\right] \mathrm{Cl}_{2} \cdot 6 \mathrm{H}_{2} \mathrm{O}$} & $71 / 28$ \\
\hline 2 & $2 b$ & $0 / 76$ & 11 & $\operatorname{Ir}(\mathrm{ppy})_{3}$ & $37 / 32$ \\
\hline 3 & 2c & $0 / 79$ & 12 & Rhodamine B & $76 / 28$ \\
\hline 4 & 2d & $77 / 26$ & 13 & Fluorescein & $71 / 36$ \\
\hline 5 & $2 e$ & $35 / 28$ & 14 & Eosin $Y$ & $81 / 23$ \\
\hline 6 & $2 f$ & $81 / 23$ & $15^{d}$ & Eosin $\mathrm{Y}-\mathrm{Na}_{2}$ & $83 / 18$ \\
\hline 7 & $2 g$ & $2 / 72$ & $16^{\mathrm{d}, \mathrm{e}}$ & Eosin $\mathrm{Y}-\mathrm{Na}_{2}$ & $0 / 0$ \\
\hline 8 & $2 h$ & $3 / 97$ & $17^{d, f}$ & $\mathrm{w} / \mathrm{o}$ Eosin $\mathrm{Y}-\mathrm{Na}_{2}$ & $38 / 10$ \\
\hline $9^{c}$ & Sulfur powder & $0 / 0$ & $18^{\mathrm{d}, \mathrm{g}}$ & Eosin $\mathrm{Y}-\mathrm{Na}_{2}$ & $88 / 6$ \\
\hline
\end{tabular}

aReaction conditions: $0.05 \mathrm{mmol}$ scale, catalyst $(2.5 \mathrm{~mol} \%$ ). Left entries: with Eosin $\mathrm{Y}-\mathrm{Na} 2$ as the photocatalyst. Right entries: with $\mathbf{2 f}$ as the sulfur donor

betermined by GC-MS analysis with anisole as an internal standard.

cSulfur powder (5.0 equiv.).

dReaction was performed in $\mathrm{CH}_{3} \mathrm{CN}$ instead of DCM.

eln dark.

'Without photocatalyst.

gWith 2.0 equiv. of $\mathbf{2 f}$ 
<smiles>CCC(P)(P)C(=O)ON1C(=O)c2ccccc2C1=O</smiles>

From $1^{\circ}, 2^{\circ}$ and $3^{\circ}$ acids

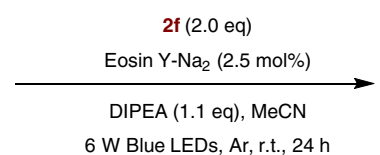

6 W Blue LEDs, Ar, r.t, 24h

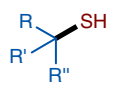

Free thiols

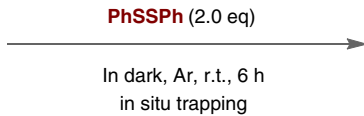

in situ trapping
${ }_{\mathrm{R}}^{\mathrm{R}} \mathrm{R}_{\mathrm{R}}^{\mathrm{S}} \mathrm{S}^{-\mathrm{Ph}}$

Disulfides
Primary acids<smiles>SCCc1ccccc1</smiles>

3, $70 \%$<smiles>SCCc1ccccc1Cl</smiles>

$6,55 \%$<smiles>CC(=O)CCCCCCCCS</smiles>

$9,81 \%$<smiles>COc1ccc(CCS)cc1</smiles>

$4,52 \%$<smiles>SCCCc1ccccc1</smiles>

7, $75 \%$<smiles>C#CCCCCCCCCS</smiles>

$10,32 \%$

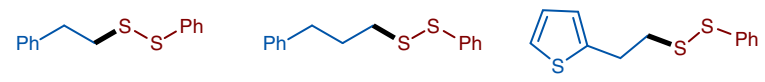

$11,72 \%$

$12,65 \%$

$13,41 \%$<smiles>ClCCCCCSSc1ccccc1</smiles>

$17,45 \%$

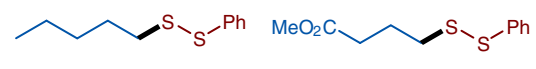

$15,80 \%$

16, $72 \%$

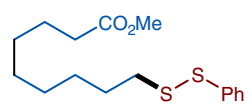

18, $70 \%$

\section{Secondary acids}

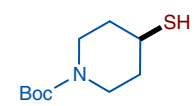

$19,40 \%$<smiles>[CH]C(=O)N1CCC(S)CC1</smiles>

$20,35 \%$

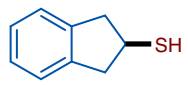

21, $34 \%$<smiles>CC1(C)C(SSc2ccccc2)C1(C)C</smiles>

22, $24 \%$<smiles>c1ccc(SSC2CCC2)cc1</smiles>

23, $60 \%$<smiles>c1ccc(SSC2CCCC2)cc1</smiles>

24, $65 \%$<smiles>c1ccc(SSC2CCCCC2)cc1</smiles>

$25,53 \%$<smiles>c1ccc(SSC2CCCCCC2)cc1</smiles>

26, $35 \%$

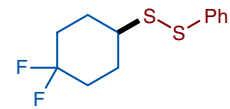

27, $73 \%$

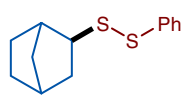

28, $64 \%$

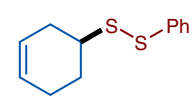

$29,50 \%$

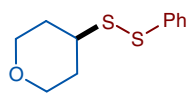

30, $54 \%$

Tertiary acids

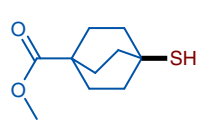

31, $56 \%$

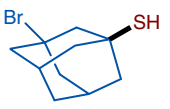

$34,60 \%$<smiles>O=C(c1ccccc1)N1CCC([Mg])CC1</smiles>

32, $16 \%$

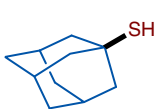

33, $52 \%$

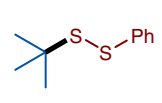

$35,25 \%$

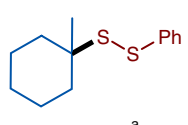

$36,39 \%^{a}$

\section{Natural products and drugs}<smiles>CCCCCCCCCCCCS</smiles><smiles>CCCCCCCCCCCCCCCCS</smiles>

$37,74 \%$

from myristic acid
38, $72 \%$ from stearic acid<smiles>CCCCCCCCCCCCCCCCCCC</smiles>

$39,62 \%$ from oleic acid<smiles>COC(=O)C(CS)NC(=O)c1ccccc1</smiles><smiles>COC(=O)C(CCS)NC(=O)c1ccccc1</smiles>

$40,37 \%$

from aspartic acid
$41,46 \%$ from glutamic acid<smiles>CC(C)(C)OC(=O)N[C@@H](CCS)C(=O)N1CCC[C@H]1C(=O)OC(C)(C)C</smiles>

$$
\text { 42, } 46 \%
$$

from dipeptide Glu-Pro<smiles>Cc1ccc(C)c(OCCCC(C)(C)S)c1</smiles>

$43,10 \%^{\mathrm{a}}$ from Gemfibrozil<smiles>SCCc1nc(-c2ccccc2)c(-c2ccccc2)o1</smiles>

44, $24 \%$ from Oxaprozin

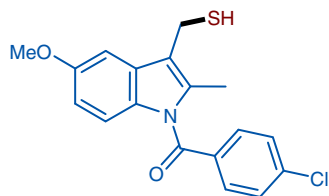

$45,49 \%$ from Indometacin

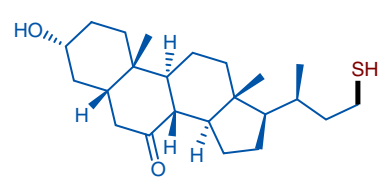

$46,32 \%$

from nutriacholic acid

Fig. 2 Substrate scope. Reactions were performed on a $0.2 \mathrm{mmol}$ scale, and trapping reactions were conducted with 2.0 equiv. of PhSSPh in dark for $6 \mathrm{~h}$. aln $\mathrm{CF}_{3} \mathrm{CH}_{2} \mathrm{OH}$.

desired free thiols (4-10) or disulfides (11-18) could be isolated in moderate to good yields. Through this decarboxylative thiolation, simple propionic acid can also be converted to the corresponding disulfide in $40 \%$ yield (14). The reaction can be well applied to cyclic carboxylic acids (19-30), and different ring sizes (22-26), including cyclopropane (22), cyclobutane (23), benzocyclopentane (21), and cycloheptane (26), all can be converted to the desired product in reasonable yields. Heterocyclic free thiols 
or disulfides, such as $\mathbf{1 9}, \mathbf{2 0}$, and $\mathbf{3 0}$, are also accessible from the corresponding carboxylic acids. Pleasingly, tertiary thiols or disulfide (31-36) can be prepared as well with this method. In particular, this visible light-mediated radical decarboxylative thiolation reaction could afford a facile access to tertiary bridgehead thiols (such as bicyclic thiol 31, 1-adamantanethiol 33 and 34) under mild reaction conditions, which are often difficult to prepare via traditional nucleophilic substitution reactions due to the steric shielding of the bridgehead position that prevents the backside attack of the nucleophiles ${ }^{59}$. The reported synthesis of $\mathbf{3 3}$ from 1-adamantyl bromide or alcohol was performed under very harsh conditions (reflux in $\mathrm{AcOH} /$ conc. aq. $\mathrm{HBr}$ ), and under the same conditions, only a trace amount of product was obtained in the synthesis of bicyclo[2.2.2] octane-1-thiol ${ }^{59,60}$. Moreover, the decarboxylative thiolation reaction can be well extended to natural occurring acids, such as oleic acid (39), aspartic acid (40), glutamic acid (41), dipeptide Glu-Pro (42), and nutriacholic acid (46). It is worth mentioning that the conversion of aspartic acid to the thiol product $\mathbf{4 0}$ is resembling a transformation of aspartic acid to cysteine via a residue manipulation. To our delight, this decarboxylative thiolation can be adopted for the late-stage modification of drugs, such as gemfibrozil (43), oxaprozin (44), and indometacin (45). In cases of $\mathbf{3 5}, \mathbf{3 6}$, and $\mathbf{4 3}$, we could observe less alkane formation when the reactions were performed in $\mathrm{CF}_{3} \mathrm{CH}_{2} \mathrm{OH}$ instead of $\mathrm{CH}_{3} \mathrm{CN}$, and thus led to a better yield. As outlined in Fig. 2, under this reaction condition, primary, secondary, and tertiary carbon radicals can all be readily generated from the corresponding alkyl NHPI esters and subsequently trapped by the sulfur donor and converted to the desired thiol or disulfide products.

Product diversification. Disulfides are important motifs in life and biological active molecules, due to their unique pharmacological and physiochemical properties ${ }^{61-66}$. To further explore the scope of this transformation, more diaryl disulfide-trapping agents were examined with dihydrocinnamic acid-derived ester 1 as a model substrate. As shown in Fig. 3a, the reactions worked well with various diaryl disulfides processing different electronic nature, affording the desired unsymmetric alkyl aryl disulfides 47-51 readily in good yields. Importantly, the conversion of carboxylic acids to disulfides via this dicarboxylic thiolation/in situ trapping protocol provides a facile approach to synthesize this type of molecules with high structural diversity. Thiols are key precursors to many pharmaceutically important compounds $s^{4-17,40-45}$. The direct decarboxylative thiolation to free thiols allows for the establishment of a rapid, in situ diversification to various thiol derivatives without isolating the free thiols, which are often smelly and unstable. As shown in Fig. 3b, the 2-phenylethane-1-thiol can readily undergo alkylation in situ with various electrophiles or Michael acceptors, to provide the corresponding sulfide products (52-57). Moreover, trapping with 4-methylbenzenesulfonyl cyanide enable the conversion of carboxylic acid to thiocyanide 58. An access to thioselenide from the corresponding carboxylic acid via an in situ reaction with diphenyl diselenide was also demonstrated with the synthesis of thioselenide 59.

A possible reaction mechanism is proposed as outlined in Fig. 4. Under the irradiation of light, the photocatalyst Eosin Y (PC) is excited and subsequently reductively quenched by DIPEA or $\mathbf{2 f}$, affording $\mathbf{P C}^{\cdot-}$ and $\mathbf{2 f}^{\prime}$ in the presence of base. The fluorescence quenching experiments also clearly showed that both DIPEA and sulfur donor $2 \mathbf{f}$ can quench the fluorescence of the photocatalyst (Supplementary Figs. 7-9). A single electron transfer (SET) from $\mathbf{P C}^{\cdot-}$ to the carboxylic acid-derived RAE afford the corresponding radical anion Int-A and concurrently regenerate the photocatalyst (Path A). As product also observed in the absence of $\mathbf{P C}$ and $\mathbf{2 f}$ showed substantial absorption in the blue light region (Supplementary Fig. 5), Path B might also

a Extension to unsymmetric disulfide synthesis
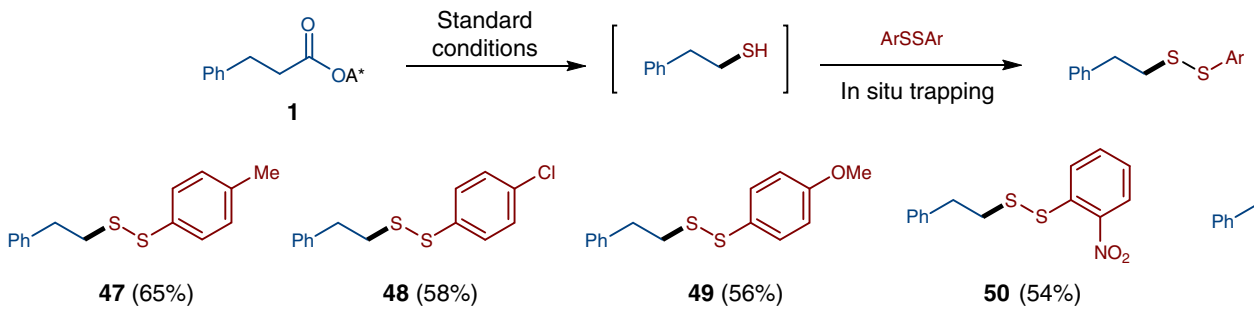<smiles>COc1ccc(SSCCc2ccccc2)cc1</smiles>

$49(56 \%)$<smiles>O=[N+]([O-])c1ccccc1SCCc1ccccc1</smiles>

$50(54 \%)$<smiles>O=[N+]([O-])c1cc(Cl)ccc1SSCCc1ccccc1</smiles>

$51(50 \%)$

b In situ diversification to sulfide, thiocyanate, thioselenide

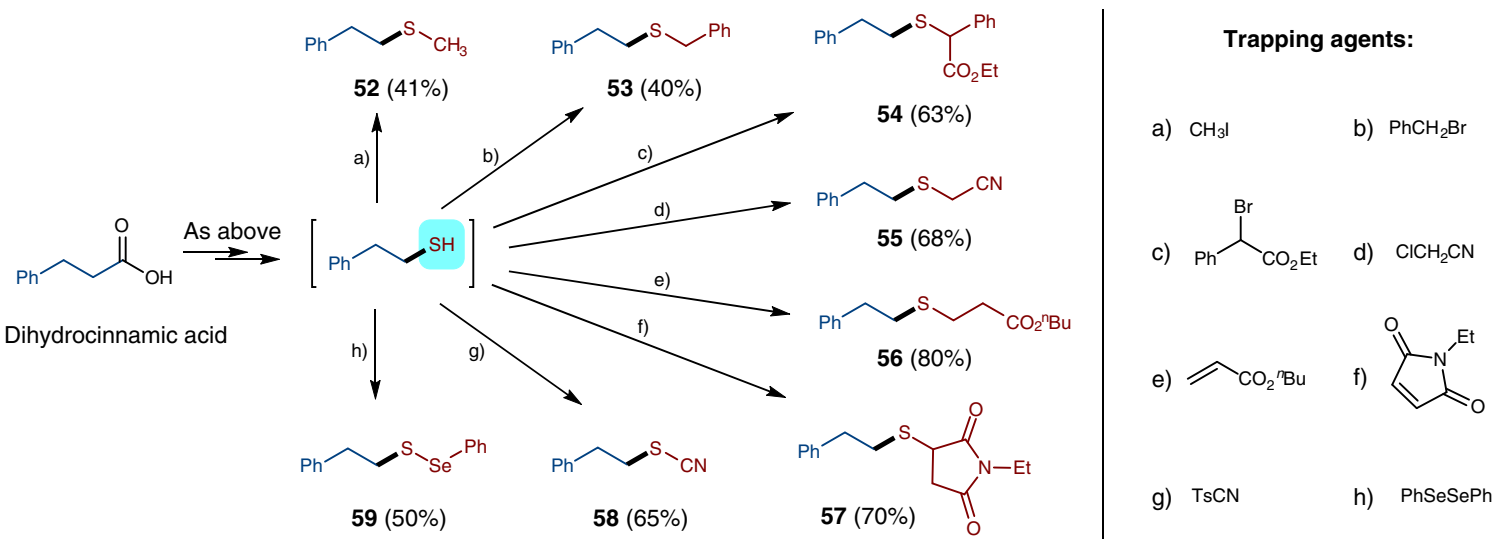

Fig. 3 Reaction extension and product diversification. a Extension to disulfide synthesis. $\mathbf{b}$ In situ diversification. 


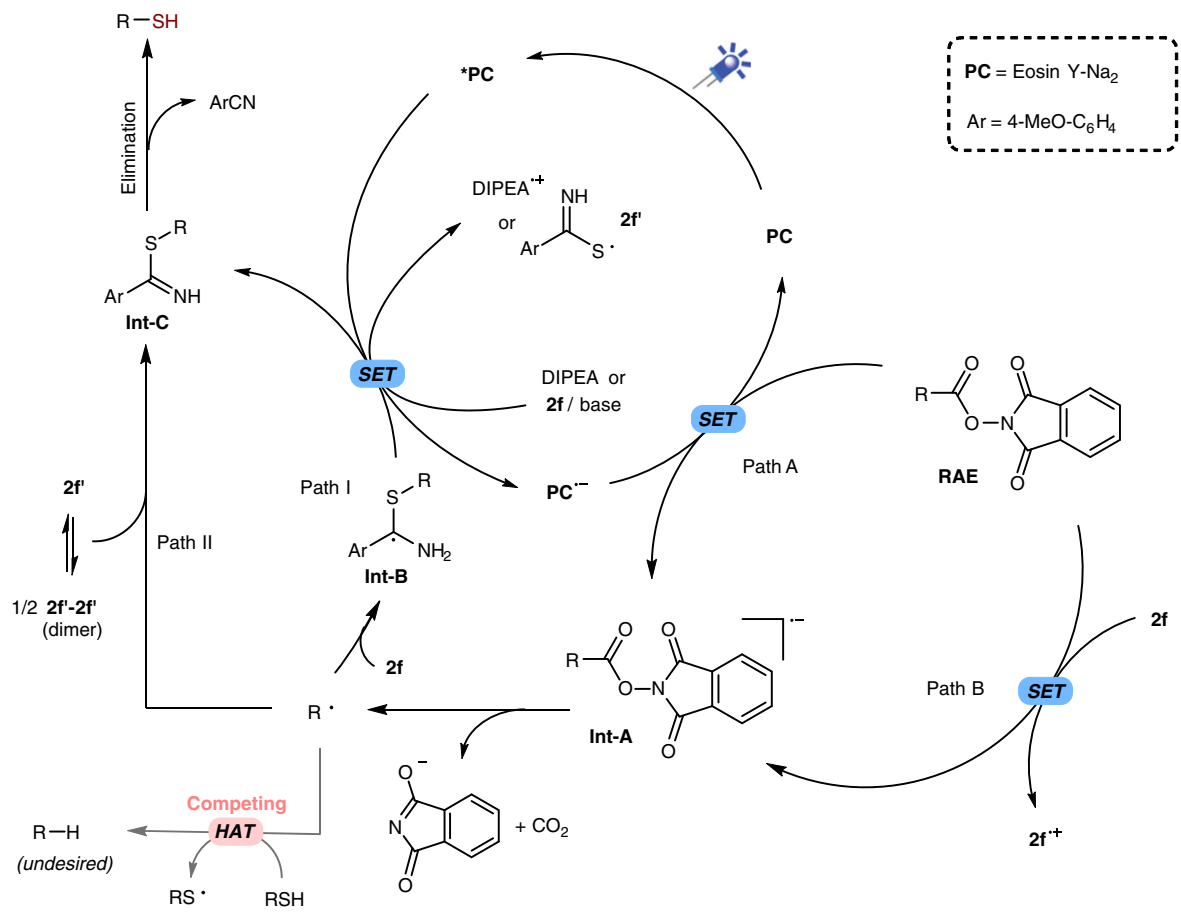

Fig. 4 Reaction pathways. A mechanistic proposal for the decarboxylative thiolation of redox-active esters (RAEs) to free thiols. SET single electron transfer, HAT hydrogen atom transfer.

involve to some extent. Int-A then undergoes fragmentation to give the alkyl radical $\mathbf{R}$. via the $\mathrm{N}-\mathrm{O}$ bond cleavage followed by the extrusion of $\mathrm{CO}_{2}$. The alkyl radical can be trapped with TEMPO (Supplementary Fig. 3). The addition of $\mathbf{R} \cdot$ to the sulfur donor $\mathbf{2} \mathbf{f}$ generate the radical intermediate $\mathbf{I n t}-\mathbf{B}^{67}$, which can be oxidized to imine Int-C by a SET to excited photocatalyst as shown as Path I. The higher yields with aryl thioamides than alkyl ones may be ascribed to the stabilization of the aryl group to radical Int-B. The beneficial effect of the electron-donating group (2d-f, entries 4-5, Table 1) might result from a favored one electron oxidation of Int-B to Int-C. Alternatively, a radical coupling of $\mathbf{R}$. and $\mathbf{2} \mathbf{f}^{\prime}$ could also afford the intermediate Int-C (Path II). As a competing process, the HAT from thiol (R-SH) to $\mathbf{R}$. will lead to the formation of the alkane side product $(\mathrm{R}-\mathrm{H})^{51,52}$, which can be suppressed by a rapid trapping of $\mathbf{R}$. with active thiolating agents via Path I or II. In the end, the desired thiol is produced after the elimination of one molecule of $A r C N^{68,69}$, which could be a relatively slow step, and a slow release of free thiols can decrease the formation of the undesired alkane product. The nitrile byproduct formation was confirmed by gas chromatography-mass spectrometry (GC-MS) analysis, and it can also be isolated by column chromatography. Therefore, the use of $\mathrm{N}$-unsubstituted thioamides is crucial for this transformation. In contrast, $\mathrm{N}$-substituted thioamide $\mathbf{2 g}$ and $\mathbf{2 h}$ are unable to form the corresponding $\mathrm{N}-\mathrm{H}$ imine intermediate Int-C.

\section{Discussion}

In conclusion, a visible light-mediated direct decarboxylative thiolation of carboxylic acid-derived RAEs to free thiols has been developed. Aryl thioamides have been identified as an effective sulfur donor and crucial to this thiolation reaction. The transformation of abundant carboxylic acid feedstock to the corresponding free thiols and their further in situ diversification allows for a rapid and general access to various pharmaceutically important compounds, such as sulfide, disulfide, thiocyanide, and thioselenide, with diverse structures, which may be utilized for the molecule library construction and benefit the related study in chemical biology and discovery of novel, biologically interesting small molecules.

\section{Methods}

General procedure for decarboxylative thiolation. To an oven-dried $10-\mathrm{ml}$ Schlenk tube equipped with a magnetic stir bar and a Teflon-coated septum screwcap was added the NHPI redox-active ester ( $0.2 \mathrm{mmol}, 1.0$ equiv.), 4methoxythiobenzamide (2f, $0.4 \mathrm{mmol}, 2.0$ equiv.), Eosin Y- $\mathrm{Na}_{2}(2.5 \mathrm{~mol} \%)$. The tube was evacuated and backfilled with argon for three cycles. The DIPEA $(0.22$ mmol, 1.1 equiv.) and dry $\mathrm{CH}_{3} \mathrm{CN}(2.0 \mathrm{ml})$ was added via a gastight syringe under argon atmosphere. Make sure the screwcap was closed, and the solvent was frozen by liquid nitrogen. Then, the screwcap was opened and the tube was evacuated for about $3 \mathrm{~min}$. The screwcap was closed and let the solvent melts in a tepid water bath. Repeat above freeze-pump-thaw procedures for 3-5 times until you no longer see the evolution of gas as the solution thaws. The tube was filled with argon and sealed, irradiated with $6 \mathrm{~W}$ blue light-emitting diode (LED) reactor and stirred at ambient temperature for $24 \mathrm{~h}$. Full experimental details (Supplementary Figs. 1-9 and Supplementary Tables 1-3) and characterization of new compounds (Supplementary Figs. 10-68) can be found in the Supplementary Methods section.

General procedure for the synthesis of disulfides. To an oven-dried 10-ml Schlenk tube equipped with a magnetic stir bar and a Teflon-coated septum screwcap was added the NHPI redox-active ester ( $0.2 \mathrm{mmol}, 1.0$ equiv.), 4 methoxythiobenzamide (2f, $0.4 \mathrm{mmol}, 2.0$ equiv.), and Eosin $\mathrm{Y}-\mathrm{Na}_{2}$ (2.5 mol\%). The tube was evacuated and backfilled with argon for three cycles. The DIPEA $\left(0.22 \mathrm{mmol}, 1.1\right.$ equiv.) and dry $\mathrm{CH}_{3} \mathrm{CN}(2.0 \mathrm{ml})$ was added via a gastight syringe under argon atmosphere. Make sure the screwcap was closed, and the solvent was frozen by liquid nitrogen. Then, the screwcap was opened and the tube was evacuated for $\sim 3 \mathrm{~min}$. The screwcap was then closed and the solvents were let to melt in a tepid water bath. Repeat above freeze-pump-thaw procedures for 3-5 times until you no longer see the evolution of gas as the solution thaws. The tube was filled with argon and sealed, irradiated with $6 \mathrm{~W}$ blue LED reactor and stirred at ambient temperature for $24 \mathrm{~h}$. Then, the $\mathrm{K}_{2} \mathrm{CO}_{3}(0.4 \mathrm{mmol}, 2.0$ equiv. $)$ and diaryl disulfide ( $0.4 \mathrm{mmol}, 2.0$ equiv.) was added under argon atmosphere. The tube stirred at ambient temperature for $6 \mathrm{~h}$ in the dark. Upon completion, the reaction mixture was carefully concentrated and the residue was further purified by flash chromatography to give the desired disulfide products. Full experimental details and characterization of new compounds can be found in the Supplementary Methods section. 


\section{Data availability}

The authors declare that all data supporting the findings of this study are available within the article and Supplementary information files, and are also available from the corresponding author upon reasonable request.

Received: 6 May 2020; Accepted: 30 September 2020;

Published online: 21 October 2020

\section{References}

1. Kennedy, J. P. et al. Application of combinatorial chemistry science on modern drug discovery. J. Comb. Chem. 10, 345-354 (2008).

2. Boström, J., Brown, D., Young, R. \& Keserü, G. M. Expanding the medicinal chemistry synthetic toolbox. Nat. Rev. Drug Discov. 17, 709-727 (2018).

3. Li, G. \& Lou, H.-X. Strategies to diversify natural products for drug discovery. Med. Res. Rev. 38, 1255-1294 (2018).

4. Dénès, F., Pichowicz, M., Povie, G. \& Renaud, P. Thiyl radicals in organic synthesis. Chem. Rev. 114, 2587-2693 (2014).

5. Dunbar, K. L., Scharf, D. H., Litomska, A. \& Hertweck, C. Enzymatic carbon-sulfur bond formation in natural product biosynthesis. Chem. Rev. 117, 5521-5577 (2017)

6. Franc, G. \& Kakkar, A. K. “Click” methodologies: efficient, simple and greener routes to design dendrimers. Chem. Soc. Rev. 39, 1536-1544 (2010).

7. Hoyle, C. E. \& Bowman, C. N. Thiol-ene click chemistry. Angew. Chem. Int. Ed. 49, 1540-1573 (2010).

8. Dreaden, E. C., Alkilany, A. M., Huang, X., Murphy, C. J. \& EI-Sayed, M. A. The golden age: gold nanoparticles for biomedicine. Chem. Soc. Rev. 41, 2740-2779 (2012).

9. Wang, X. et al. Palladium-catalyzed enantioselective thiocarbonylation of styrenes. Angew. Chem. Int. Ed. 58, 12264-12270 (2019).

10. Ouhib, F. et al. A switchable domino process for the construction of novel $\mathrm{CO}_{2}$-sourced sulfur-containing building blocks and polymers. Angew. Chem. Int. Ed. 131, 11894-11899 (2019).

11. Laudadio, G. et al. Sulfonyl fluoride synthesis through electrochemical oxidative coupling of thiols and potassium fluoride. J. Am. Chem. Soc. 141, 11832-11836 (2019).

12. Kang, Y. S. et al. Ligand-promoted RhIII-catalyzed thiolation of benzamides with a broad disulfide scope. Angew. Chem. Int. Ed. $\mathbf{5 8}$ 9099-9103 (2019)

13. Liu, D., Ma, H.-X., Fang, P. \& Mei, T.-S. Nickel-catalyzed thiolation of aryl halides and heteroaryl halides through electrochemistry. Angew. Chem. Int. Ed. 58, 5033-5037 (2019).

14. Yang, X.-H. et al. Catalytic hydrothiolation: counterion-controlled regioselectivity. J. Am. Chem. Soc. 141, 3006-3013 (2019).

15. Zhang, Y., Xu, X. \& Zhu, S. Nickel-catalysed selective migratory hydrothiolation of alkenes and alkynes with thiols. Nat. Commun. 10, 1752 (2019).

16. McKinnell, R. M. et al. Discovery of TD-0212, an orally active dual pharmacology AT1 antagonist and neprilysin inhibitor (ARNI). ACS Med. Chem. Lett. 10, 86-91 (2019).

17. He, J. et al. Catalytic decarboxylative radical sulfonylation. Chem 6, 1149-1159 (2020).

18. Alegre-Cebollada, J., Kosuri, P., Rivas-Pardo, J. A. \& Fernández, J. M. Direct observation of disulfide isomerization in a single protein. Nat. Chem. 3 882-887 (2011).

19. Góngora-Benítez, M., Tulla-Puche, J. \& Albericio, F. Multifaceted roles of disulfide bonds. Peptides as therapeutics. Chem. Rev. 114, 901-926 (2014).

20. Poole, L. B. The basics of thiols and cysteines in redox biology and chemistry. Free Radic. Biol. Med. 80, 148-157 (2015).

21. Spicer, C. D. \& Davis, B. G. Selective chemical protein modification. Nat. Commun. 5, 4740 (2014)

22. Krall, N., da Cruz, F., Boutureira, O. \& Bernardes, G. Site-selective proteinmodification chemistry for basic biology and drug development. Nat. Chem. 8 103-113 (2015).

23. deGruyter, J. N., Malins, L. R. \& Baran, P. S. Residue-specific peptide modification: a chemist's guide. Biochemistry 56, 3863-3873 (2017).

24. Xuan, J., Zhang, Z.-G. \& Xiao, W.-J. Visible-light-induced decarboxylative functionalization of carboxylic acids and their derivatives. Angew. Chem. Int. Ed. 54, 15632-15641 (2015).

25. Huang, H., Jia, K. \& Chen, Y. Radical decarboxylative functionalizations enabled by dual photoredox catalysis. ACS Catal. 6, 4983-4988 (2016).

26. Schwarz, J. \& König, B. Decarboxylative reactions with and without light-a comparison. Green. Chem. 20, 323-361 (2018).

27. Murarka, S. $N$-(acyloxy) phthalimides as redox-active esters in cross-coupling reactions. Adv. Synth. Catal. 360, 1735-1753 (2018).
28. Fawcett, A. et al. Photoinduced decarboxylative borylation of carboxylic acids Science 357, 283-286 (2017)

29. Candish, L., Teders, M. \& Glorius, F. Transition-metal-free, visible-lightenabled decarboxylative borylation of aryl $\mathrm{N}$-hydroxyphthalimide esters. J. Am. Chem. Soc. 139, 7440-7443 (2017).

30. Wang, D., Zhu, N., Chen, P., Lin, Z. \& Liu, G. Enantioselective decarboxylative cyanation employing cooperative photoredox catalysis and copper catalysis. $J$ Am. Chem. Soc. 139, 15632-15635 (2017).

31. Mao, R., Frey, A., Balon, J. \& Hu, X. Decarboxylative C $\left(\mathrm{sp}_{3}\right)-\mathrm{N}$ crosscoupling via synergetic photoredox and copper catalysis. Nat. Catal. 1, 120-126 (2018).

32. Ma, J. et al. Synthesis of $\beta$-substituted $\gamma$-aminobutyric acid derivatives through enantioselective photoredox catalysis. Angew. Chem. Int. Ed. 57, 11193-11197 (2018).

33. Wang, C. et al. Visible-light-driven, copper-catalyzed decarboxylative $\mathrm{C}\left(\mathrm{sp}_{3}\right)$ $-\mathrm{H}$ alkylation of glycine and peptides. Angew. Chem. Int. Ed. 57, 15841-15846 (2018)

34. Proctor, R. S. J., Davis, H. J. \& Phipps, R. J. Catalytic enantioselective miniscitype addition to heteroarenes. Science 360, 419-422 (2018).

35. Fu, M.-C., Shang, R., Zhao, B., Wang, B. \& Fu, Y. Photocatalytic decarboxylative alkylations mediated by triphenylphosphine and sodium iodide. Science 363, 1429-1434 (2019).

36. Qin, T. et al. A general alkyl-alkyl cross-coupling enabled by redox-active esters and alkylzinc reagents. Science 352, 801-805 (2016).

37. Huihui, K. M. M. et al. Decarboxylative cross-electrophile coupling of N-hydroxyphthalimide esters with aryl iodides. J. Am. Chem. Soc. 138 5016-5019 (2016)

38. Xue, W. \& Oestreich, M. Copper-catalyzed decarboxylative radical silylation of redox-active aliphatic carboxylic acid derivatives. Angew. Chem. Int. Ed. 56, 11649-11652 (2017).

39. Liu, X. G. et al. Decarboxylative Negishi coupling of redox-active aliphatic esters by cobalt catalysis. Angew. Chem. Int. Ed. 57, 13096-13100 (2018).

40. Scott, K. A. \& Njardarson, J. T. Analysis of US FDA-approved drugs containing sulfur atoms. Top. Curr. Chem. 376, 1-34 (2018)

41. Feng, M., Tang, B., Liang, S. \& Jiang, X. Sulfur containing scaffolds in drugs: synthesis and application in medicinal chemistry. Curr. Top. Med. Chem. 16, 1200-1216 (2016)

42. Ilardi, E. A., Vitaku, E. \& Njardarson, J. T. Data-mining for sulfur and fluorine: an evaluation of pharmaceuticals to reveal opportunities for drug design and discovery: miniperspective. J. Med. Chem. 57, 2832-2842 (2014).

43. Wimmer, A. \& König, B. Photocatalytic formation of carbon-sulfur bonds. Beilstein J. Org. Chem. 14, 54-83 (2018)

44. Jin, Y., Yang, H. \& Fu, H. An N-(acetoxy) phthalimide motif as a visible-light pro-photosensitizer in photoredox decarboxylative arylthiation. Chem. Commun. 52, 12909-12912 (2016).

45. Wei, L., Wu, C., Tung, C.-H., Wang, W. \& Xu, Z. Decarboxylative sulfenylation of amino acids via metallaphotoredox catalysis. Org. Chem. Front. 6, 3224-3227 (2019).

46. Na, C. G., Ravelli, D. \& Alexanian, E. J. Direct decarboxylative functionalization of carboxylic acids via $\mathrm{O}-\mathrm{H}$ hydrogen atom transfer. J. Am. Chem. Soc. 142, 44-49 (2020).

47. Gianatassio, R. et al. Simple sulfinate synthesis enables C-H trifluoromethylcyclopropanation. Angew. Chem. Int. Ed. 53, 9851-9855 (2014).

48. Barton, D. H. R., Crich, D. \& Motherwell, W. B. New and improved methods for the radical decarboxylation of acids. J. Chem. Soc. Chem. Commun. 939-941 https://pubs.rsc.org/en/content/articlelanding/1983/c3/ c39830000939\#!divAbstract (1983).

49. Barton, D. H. R., Lacher, B., Misterkiewicz, B. \& Zard, S. Z. The invention of radical reactions: Part XVII. A decarboxylative sulphonylation of carboxylic acids. Tetrahedron 44, 1153-1158 (1988).

50. Guin, J., Fröhlich, R. \& Studer, A. Thiol-catalyzed stereoselective transfer hydroamination of olefins with $\mathrm{N}$-aminated dihydropyridines. Angew. Chem. Int. Ed. 47, 779-782 (2008)

51. Okada, K., Okamoto, K. \& Oda, M. A new and practical method of decarboxylation: photosensitized decarboxylation of $\mathrm{N}$-acyloxyphthalimides via electron-transfer mechanism. J. Am. Chem. Soc. 110, 8736-8738 (1988).

52. Newcomb, M., Glenn, A. G. \& Manek, M. B. Rate constants and arrhenius functions for hydrogen atom transfer from tert-butyl thiol to primary alkyl radicals. J. Org. Chem. 54, 4603-4606 (1989).

53. Chauvin, J.-P. R., Griesser, M. \& Pratt, D. A. Hydropersulfides: H-atom transfer agents par excellence. J. Am. Chem. Soc. 139, 6484-6493 (2017)

54. Poon, J.-F. \& Pratt, D. A. Recent insights on hydrogen atom transfer in the inhibition of hydrocarbon autoxidation. Acc. Chem. Res. 51, 1996-2005 (2018)

55. Roth, P. J., Boyer, C., Lowe, A. B. \& Davis, T. P. RAFT polymerization and thiol chemistry: a complementary pairing for implementing modern macromolecular design. Macromol. Rapid Commun. 32, 1123-1143 (2011). 
56. Moad, G., Rizzardo, E. \& Thang, S. H. Radical addition-fragmentation chemistry in. Polym. Synth. Polym. 49, 1079-1131 (2008).

57. Cossar, B. C., Fournier, J. O., Fields, D. L. \& Reynolds, D. D. Preparation of thiols. J. Org. Chem. 27, 93-95 (1962).

58. Wardell, J. L. In The Chemistry of the Thiol Group (ed. Patai, S.), Part 1, 179-211 (Wiley, New York, 1974).

59. Tkachenko, B. A. et al. Functionalized nanodiamonds part 3: thiolation of tertiary/bridgehead alcohols. Org. Lett. 8, 1767-1770 (2006).

60. Moya-López, J. F. et al. Studies on the diastereoselective oxidation of 1-thio- $\beta$ d-glucopyranosides: synthesis of the usually less favoured RS sulfoxide as a single diastereoisomer. Org. Biomol. Chem. 13, 1904-1914 (2015).

61. Musiejuka, M. \& Witt, D. Recent developments in the synthesis of unsymmetrical disulfanes (disulfides). A review. Org. Prep. Proc. Int. 47, 95-131 (2015).

62. Xiao, X., Feng, M. \& Jiang, X. New design of a disulfurating reagent: facile and straightforward pathway to unsymmetrical disulfanes by copper-catalyzed oxidative cross-coupling. Angew. Chem. Int. Ed. 55, 14121-14125 (2016).

63. Xiao, X., Xue, J. \& Jiang, X. Polysulfurating reagent design for unsymmetrical polysulfide construction. Nat. Commun. 9, 2191 (2018).

64. Wang, W., Lin, Y., Ma, Y., Tung, C.-H. \& Xu, Z. Cu-catalyzed electrophilic disulfur transfer: synthesis of unsymmetrical disulfides. Org. Lett. 20, 3829-3832 (2018).

65. Huang, P., Wang, P., Tang, S., Fu, Z. \& Lei, A. Electro-oxidative S-H/S-H cross-coupling with hydrogen evolution: facile access to unsymmetrical disulfides. Angew. Chem. Int. Ed. 57, 8115-8119 (2018).

66. Chauvin, J.-P. R., Griesser, M. \& Pratt, D. A. The antioxidant activity of polysulfides: it's radical! Chem. Sci. 10, 4999-5010 (2019).

67. Smith, R. A., Fu, G., McAteer, O., Xu, M. \& Gutekunst, W. R. Radical approach to thioester containing polymers. J. Am. Chem. Soc. 141, 1446-1451 (2019).

68. Khodade, V. S. \& Toscano, J. P. Development of S-substituted thioisothioureas as efficient hydropersulfide precursors. J. Am. Chem. Soc. 140, 17333-17337 (2018).

69. Rad, M. N. S. \& Maghsoudi, S. Two-step three-component process for one-pot synthesis of 8-alkylmercaptocaffeine derivatives. RSC Adv. 6, 70335-70342 (2016).

\section{Acknowledgements}

We gratefully acknowledge National Natural Science Foundation of China (No. 21602028), the Recruitment Program of Global Experts, and Fuzhou University for the financial support.

\section{Author contributions}

T.C. and T.X. contributed equally to this work. T.C. developed the reactions, and contributed to the reaction scope investigation, mechanistic study, and product derivatization. T.X. carried out most substrate synthesis, and contributed to the study of reaction scope, product diversification, and reaction mechanism. R.X. and X.S. participated in the synthesis of substrates. S.L. conceived this concept and prepared this manuscript with feedback from T.C. and T.X.

\section{Competing interests}

The authors declare no competing interests.

\section{Additional information}

Supplementary information is available for this paper at https://doi.org/10.1038/s41467020-19195-w.

Correspondence and requests for materials should be addressed to S.L.

Peer review information Nature Communications thanks Hua Wang and the other, anonymous, reviewer(s) for their contribution to the peer review of this work. Peer reviewer reports are available.

Reprints and permission information is available at http://www.nature.com/reprints

Publisher's note Springer Nature remains neutral with regard to jurisdictional claims in published maps and institutional affiliations.

cc) (i) Open Access This article is licensed under a Creative Commons Attribution 4.0 International License, which permits use, sharing, adaptation, distribution and reproduction in any medium or format, as long as you give appropriate credit to the original author(s) and the source, provide a link to the Creative Commons license, and indicate if changes were made. The images or other third party material in this article are included in the article's Creative Commons license, unless indicated otherwise in a credit line to the material. If material is not included in the article's Creative Commons license and your intended use is not permitted by statutory regulation or exceeds the permitted use, you will need to obtain permission directly from the copyright holder. To view a copy of this license, visit http://creativecommons.org/ licenses/by/4.0/.

(C) The Author(s) 2020 